\title{
Effect of Unsuccessful Weight Loss Dietary Interventions on Cardiovascular Risk
}

\section{Belirlenen Hedeflere Ulaşamayan Kilo Verdirici Diyet Girişimlerinin Kardiyovasküler Risk Üzerine Etkisi}

\author{
Eda Türe ${ }^{1}$,Ertan Mert ${ }^{* 2}$, Yücel Uysal ${ }^{2}$
}

\begin{abstract}
Objective: Increasing incidence of obesity in our country and all over the world and due to concomitant diseases has become a national health problem. Obesity is described as excessive fat accumulation and storing in the body and according to World Health Organization data on 300 million people are affected. Obesity is an independent risk factor for cardiovascular diseases and obese patients often carry increased risk for the development of hypertension, dyslipidemia and Type 2 diabetes. Weight reduction provides an improvement in obesity related comorbid conditions. For this purpose, to determine the effectiveness of diet in the prevention of obesity-related cardiovascular risk factors and in order to see the effects of diet on 10-year risk of cardiovascular disease, a prospective and observational clinical study was performed in Mersin University Family Medicine clinic between January and August 2014 with 178 female cases presented with obesity. Methods: Cases were followed with the six-month diet for obesity treatment. At the first advent of cases and 6 months after treatment with diet, staging of obesity according to waist circumference and body mass index, staging of blood pressure and laboratory data (lipid profiles) were performed and 'Framingham Heart Study' based on the results generated seven parameters (age, sex, blood pressure, LDL-cholesterol, HDL-cholesterol, cigarette use, diabetes and whether they are) scoring system using the 10-year cardiovascular risk were calculated. Results: After dietary treatment of patients, significant reduction in staging and laboratory data could not be detected but within 10 years of cases a significant reduction in the risk of developing cardiovascular disease was found. Conclusion: In obese patients, obesity and associated parameters we are able to provide small improvements in the unseen as significant, even for these cases, our rates of protection from the risk of cardiovascular disease can be quite significant.
\end{abstract}

Key words: Cardiovascular disease risk, nutrition, Framingham risk scoring, obesity

\section{ÖZET}

Amaç: Obezite tüm dünyada ve ülkemizde artan sıklığı ve eşlik eden hastalıkları nedeniyle ulusal bir sağlık sorunu haline gelmiștir. Vücutta aşırı ölçüde yağ birikmesi ve depolanması olarak tarif edilen obezite, Dünya Sağlık Örgütü verilerine göre 300 milyondan fazla insanı etkilemektedir. Obezite kardiyovasküler hastalıklar için bağımsız bir risk faktörüdür ve obez kişiler sıklıkla hipertansiyon, dislipidemi ve Tip 2 diyabet gibi hastalıkların gelişimi açısından artan risk taşırlar. Kilo azaltılması obeziteye bağlı bu komorbid durumlarda bir düzelme sağlar. Bu amaçla, obezite ile ilişkili kardiyovasküler risk faktörlerinin önlenmesinde beslenmenin etkinliğini saptamak ve beslenmenin 10 yıllık kardiyovasküler hastalık riski üzerindeki etkilerini görmek amacıyla Mersin Üniversitesi Aile Hekimliği Kliniğine Ocak 2014-Ağustos 2014 tarihleri arasında obezite nedeni ile başvuran 178 kadın vaka ile prospektif ve gözlemsel bir çalışma yürütüldü. Gereç ve Yöntem: Çalışmaya alınan vakalar obeziteye yönelik olarak 6 aylık beslenme tedavisi ile takip edildi. Vakaların ilk geliş ve 6 aylık beslenme tedavisi sonrası vücut kitle indeksi, kan basıncı, laboratuvar verileri (lipid profili) ve 'Framingham Kalp Çalışması' sonuçlarına dayanılarak oluşturulmuş yedi parametreli (yaş, cinsiyet, kan basınc1, LDL-kolesterol, HDL-kolesterol, sigara kullanıp kullanmama ve diyabet olup olmama) skorlama sistemi kullanılarak 10 yıllık kardiyovasküler risk hesaplamaları yapıldı. Bulgular: Vakaların beslenme tedavisi öncesi değerlendirilen parametrelerinde beslenme tedavisi sonrası anlamlı düşüşler saptanamadı, fakat vakaların 10 yıl içindeki kardiyovasküler hastalık geliştirme risklerinde anlamlı azalma bulundu. Sonuç: Obez vakalarda obezite ve ilişkili parametrelerde anlamlı gibi görünmeyen çok küçük iyileştirmeler sağlayabildiğimizde dahi bu vakaları kardiyovasküler hastalık riskinden koruma oranlarımız oldukça anlamlı olabilmektedir. Anahtar kelimeler: Beslenme, Framingham risk skorlaması, kardiyovasküler hastalık riski, obezite

Received Date/Geliş Tarihi: 26.02.2018, Accepted Date/Kabul Tarihi: 24.04.2018

${ }^{1}$ T.C. Sağlık Bakanlığı, Samsun Eğitim ve Araştırma Hastanesi, SAMSUN

${ }^{2}$ Mersin Üniversitesi Tıp Fakültesi Aile Hekimliği Anabilim Dalı, MERSİN

*Address for Correspondence/Yazışma Adresi: Ertan Mert, Mersin Üniversitesi Tıp Fakültesi Aile Hekimliği Anabilim Dalı MERSIN E-mail: drertanmert@yahoo.com

Türe E, Mert E, Uysal Y. Belirlenen Hedeflere Ulaşamayan Kilo Verdirici Diyet Girişimlerinin Kardiyovasküler Risk Üzerine Etkisi. TJFMPC, 2018;12(3): 156-161. DOI: 10.21763/tjfmpc.452404 


\section{GíRiş}

Günümüzde en önemli sağllk sorunlarından biri haline gelen obezite, dünyadaki hızlı prevalans artışı ve beraberinde getirdiği hastalık riskleriyle güncelliğini korumaktadır. Obezite prevalansında görülen artışın nedenleri, artan teknoloji ile beraber kolaylaşan yaşam biçimine bağlı fiziksel aktivitede azalma ve modern yaşamdaki beslenme alışkanlıklarındaki değişimdir. Ayaküstü (fast food) hızlı yenen sağl1ksız besinlerle karbonhidrattan ve rafine şekerden zengin, bitkisel liflerden fakir, aşırı yağlı beslenme şekli obeziteye yol açan önemli faktörlerden birisidir. ${ }^{1}$ Kardiyovasküler hastalıklar da obeziteye eşlik eden hastalık gruplarından biridir ve kardiyovasküler hastalıklar, son yıllarda tüm dünyada olduğu gibi, bizim ülkemizde de mortalitenin ve morbiditenin başlıca nedeni olarak dikkati çekmektedir ve prevalansı giderek artmaktadir. $^{2}$

TEKHARF 2017 (Türk Erişkinlerinde Kalp Hastalığı ve Risk Faktörleri) çalışmasında da belirtildiği üzere; Türkiye'de yaklaşık 3.5 milyon koroner kalp hastası bulunmaktadır, ayrıca nüfusun artması ve yaşlanmasına bağlı olarak bu sayının her y1l ortalama $\% 4$ oranında artacağ öngörülmektedir. ${ }^{3}$

Yaşam tarzı değişiklikleri ile modifiye edilebilen sigara, obezite, fiziksel inaktivite, yaşam tarzı değişiklikleri ve/veya ilaçlarla modifiye edilebilen lipit bozuklukları, hipertansiyon, diyabetes mellitus ve insülin rezistansının yanı sıra yaş, cinsiyet ve aile hikayesi gibi modifiye edilemeyen faktörler ve leptin, homosistein, trombotik ve inflamatuar faktörler gibi yeni risk faktörleri kardiyovasküler hastalıkların başlangıcında ve progresyonunda önemli rol oynamaktadır. ${ }^{4}$ Kardiyovasküler hastalıklar klinik olarak ortaya çıktıktan sonra uygulanan tıbbi, cerrahi ve girişimsel tedavi yöntemleri belirli olup oldukça yüksek bir maliyet gerektirmektedir. Oysa ki, koroner ateroskleroz önemli ölçüde önlenebilen ve geciktirilebilen bir hastalıktır. Bu nedenle risk faktörleri tanımlanmış ve henüz hastalanmamış olanlarda primer koruma, hastalığı olanlarda tekrarları önlemek için ise tersiyer koruma çalışmalarına ağırlık verilmesinin önemi açıktır. primordial korumanın en başta gelen amac1, risk faktörlerinin gelişmesini önlemektir. Özellikle modifiye edilebilen risk faktörlerinin izlenmesi ve erken müdahale edilmesi çok büyük önem taşır. Tüm hastalara ve hasta olma olasılığı olan normal popülasyona, risk faktörlerinin gelişmesini önleyecek bir yaşam tarzını benimsemelerinin önemi vurgulanmalıdır. $\mathrm{Bu}$ amaçla kardiyovasküler risk faktörlerinin tek tek ortaya konması, hastanın total kardiyovasküler riskinin belirlenmesi ve uygulanacak yaşam tarzı değişiklikleri ve uygun medikal tedavi ile hastanın bulunduğu risk grubuna ait hedef değerlere ulaştırılması ve bu değerlerin korunması gerekmektedir.

Bazen yaşam tarzı değişikliklerinde yaratılan küçük olumlu farklar bile kardiyovasküler risk faktörlerinde anlamlı iyileşmeye neden olabilmektedir. Bu çalışmada başlangıçta belirlenen hedeflere ulaşamayan fazla kilolu ve obez vakalarda uygulanan beslenme tedavisinin kardiyovasküler risk faktörleri üzerinde ne düzeyde etkileri olduğu araştırılmıştır.

\section{GEREÇ VE YÖNTEM}

Çalışma; Mersin Üniversitesi Tıp Fakültesi Aile Hekimliği Polikliniği'ne Ocak 2014-Ağustos 2014 tarihleri arasında obezite nedeni ile başvuran ve kilo vermeye yönelik beslenme talep eden vakalardan toplanan veriler ile gerçekleştirilmiştir. Çalışma öncesi Mersin Üniversitesi Tıp Fakültesi Tıbbi Araştırmalar Etik Kurulu'nun 19.07.2013 tarih ve 2013/256 numaralı onayı alınmıștır. Çalışmaya alınan 178 vaka başlangıçta hedeflenen 6 aylık kilo verme hedeflerine ulaşamamış vakalardan seçilmiştir. Vakalarda Framingham Risk Skorlamasınının yapılabileceği parametreler beslenme öncesi ve beslenme sonrası dönemde kaydedilmiştir. Bunlar; yaş, LDL kolesterol, total kolesterol, HDL kolesterol, kan basinc1, diyabet varlığı, sigara kullanımıdır. ${ }^{5,6}$ Uygulanan kilo verdirme amaçlı beslenmenin Framingham risk skorlaması parametreleri üzerindeki ayrı ayrı etkisi ve toplam Framingham risk skoruna etkisi analiz edilmiştir.

Çalışmada, tanımlayıcı özellikler, kategorik verilerde $n$ ve $\%$ değerleri ile, sürekli verilerde ise dağılım özelliklerine göre uygun yerlerde ortalama \pm standart sapma değerleri ile incelenmiştir. Kategorik verilerin karşılaştırılmasında, Fisher kesin olasılık testi kullanılmıştır. Sürekli verilerin dağılımı, Kolmogrov-Smirnov/ShapiroWilk testleri ile incelenmiştir. Normal dağılım göstermeyen sürekli verilerin karşılaştırılmasında, MannWhitney U testi ve Kruskal Wallis testi kullanım alanına uygun yerlerde kullanılmıştır. Normal dağılım gösteren sürekli verilerin karşılaştırılmasında, bağımsız gruplarda tek yönlü ANOVA testi kullanılmıştır. İstatistiksel anlamlılık için $\mathrm{p}<0,05$ kabul edilmiştir.

\section{BULGULAR}

178 vakanın tamamı kadındır. Ortalama yaş 46,3土 9,6 yıl ( min. 30, max.68) bulundu. Vakaların yaş, diyabet durumu ve sigara kullanımı dağılımı Tablo 1 'de gösterilmiştir. 


\begin{tabular}{|l|l|l|}
\hline \multicolumn{3}{|l|}{ Tablo 1. Vakaların yaş, diyabet durumu ve sigara kullanımı dağılımı (toplam n=178) } \\
\hline & $\mathbf{n}$ & $\mathbf{\%}$ \\
\hline Yaş & & \\
\hline $30-34$ & 22 & 12,4 \\
\hline $35-39$ & 26 & 14,6 \\
\hline $40-44$ & 38 & 21,3 \\
\hline $45-49$ & 22 & 12,4 \\
\hline $50-54$ & 28 & 15,7 \\
\hline $55-59$ & 25 & 14,1 \\
\hline $60-64$ & 17 & 9,5 \\
\hline Diyabet & & \\
\hline Mevcut & 7 & 3,9 \\
\hline Mevcut değil & 171 & 96,1 \\
\hline Sigara & & \\
\hline Kullanıyor & 19 & 10,6 \\
\hline Kullanmıyor & 159 & 89,4 \\
\hline
\end{tabular}

Vakaların beslenme öncesi ve beslenme sonrası dönemde kaydedilen vücut kitle indeksi, LDL

Vakaların yaş aralıklarına göre dağılımı birbirine yakın idi. En fazla vakanın toplandığ 1 yaş aralığ 40-44 yaş arası idi. Vakaların \%3,9'unda diyabet mellitus mevcuttu, ayrica \%10,6'sinın sigara kullandığ 1 tespit edildi.

Vücut kitle indeksi açısından çalışmanın başlangıcında vakaların büyük çoğunluğu $(\% 44,9)$ klas 1 obezite grubunda idi. Vücut kitle indeksinde değişim açısından beslenme öncesi ve beslenme basıncı düzeylerindeki değişimlerin istatistiksel olarak anlamlı olmadığı bulundu.

Tablo 3'de yaş gruplarına göre vakaların beslenme öncesi ve beslenme sonrası dönemde Framingham risk skoruna göre ortalama risk değerleri gösterilmiştir. Beslenme sonrasında 30-34 yaş aralığı dışındaki tüm yaş gruplarında ortalama riskte istatistiksel olarak anlamlı düzeyde azalma tespit edilmiştir.

\section{TARTISMA}

Vakalarda araştırılan parametrelerden yaş, cinsiyet, LDL-kolesterol, HDL-kolesterol, kan basinc1, diyabet ve sigara içme durumu verileri kullanılarak Framingham Risk Skorlamasına göre vakaların 10 yıl içinde kardiyovasküler hastalıkla karşılaşma riskleri hesaplandı ve yaş gruplarına göre sınıflandırıldı. 35-64 yaş aralığındaki tüm yaş gruplarındaki vakalarda kardiyovasküler hastalık riskinde istatistiksel olarak anlamlı azalmalar görüldü. En fazla risk azalması 60-64 yaş grubunda (\%15.6'dan \%13.2'ye; -2.4 düşüş) bulundu. Yaş gruplarından bağımsız tüm vakalardaki ortalama risk azalması -1.4 olarak hesaplanmıştır. kolesterol, total kolesterol, HDL kolesterol ve kan basıncı değerleri Tablo 2'de gösterilmiştir.

sonrası dönemler arasında istatistiksel olarak anlamlı bir fark tespit edilmedi. Çalışmanın başlangıcında vakaların \%59,6'sının LDL kolesterolü $130 \mathrm{mg} / \mathrm{dL}$ 'nin altında olduğu bulundu. Beslenme öncesi ve beslenme sonrası dönemlerde LDL kolesterol değişimi arasında istatistiksel olarak anlamlı bir fark tespit edilmedi. Ayrıca beslenme öncesi ve beslenme sonrası dönemlerde vakaların total kolesterol, HDL kolesterol ve kan

Framingham risk skorlaması ayrıntılı incelendiğinde; değiştirilebilen risk faktörleri olarak LDL-kolesterol, kolesterol, HDL-kolesterol, kan basıncı ve sigara içilmesi olduğu görülmektedir. $\mathrm{Bu}$ risk faktörleri bağlamında en düşük risk grubunda olan bir vaka ile en yüksek risk grubunda olan bir vakanın skoru -5 ile 9 arasında yani 14 puan değişmektedir. Framingham risk skorlamasında toplam skorla bu skora karşılık gelen risk yüzdesi tablolarına baktığımızda kadınlarda 0 puanın $\% 2$ riske karşılık geldiği ve 14 puanın $\% 20$ riske karşılık geldiği görülmektedir.

Araştırmamızda risk faktörleri açısından parametreleri ayrı ayrı değerlendirdiğimizde, beslenme sonrası vakaların değerlerinde belirgin iyileşmeler sağlayamadığımız veya iyileşmelerin çok az düzeylerde olduğu bulunmuşsa da ayrı ayrı parametrelerdeki tüm bu sınırlı düzelmelerin total kardiyovasküler riskler üzerindeki etkisinin önemli ve anlamlı düzeylerde olduğu görülmüştür. Özellikle ileri yaş gruplarındaki risk azalmasının ilaçlarla elde edilen olumlu iyileştirmelerle kıyaslanabilir düzeylerde olduğu görülmüştür. 


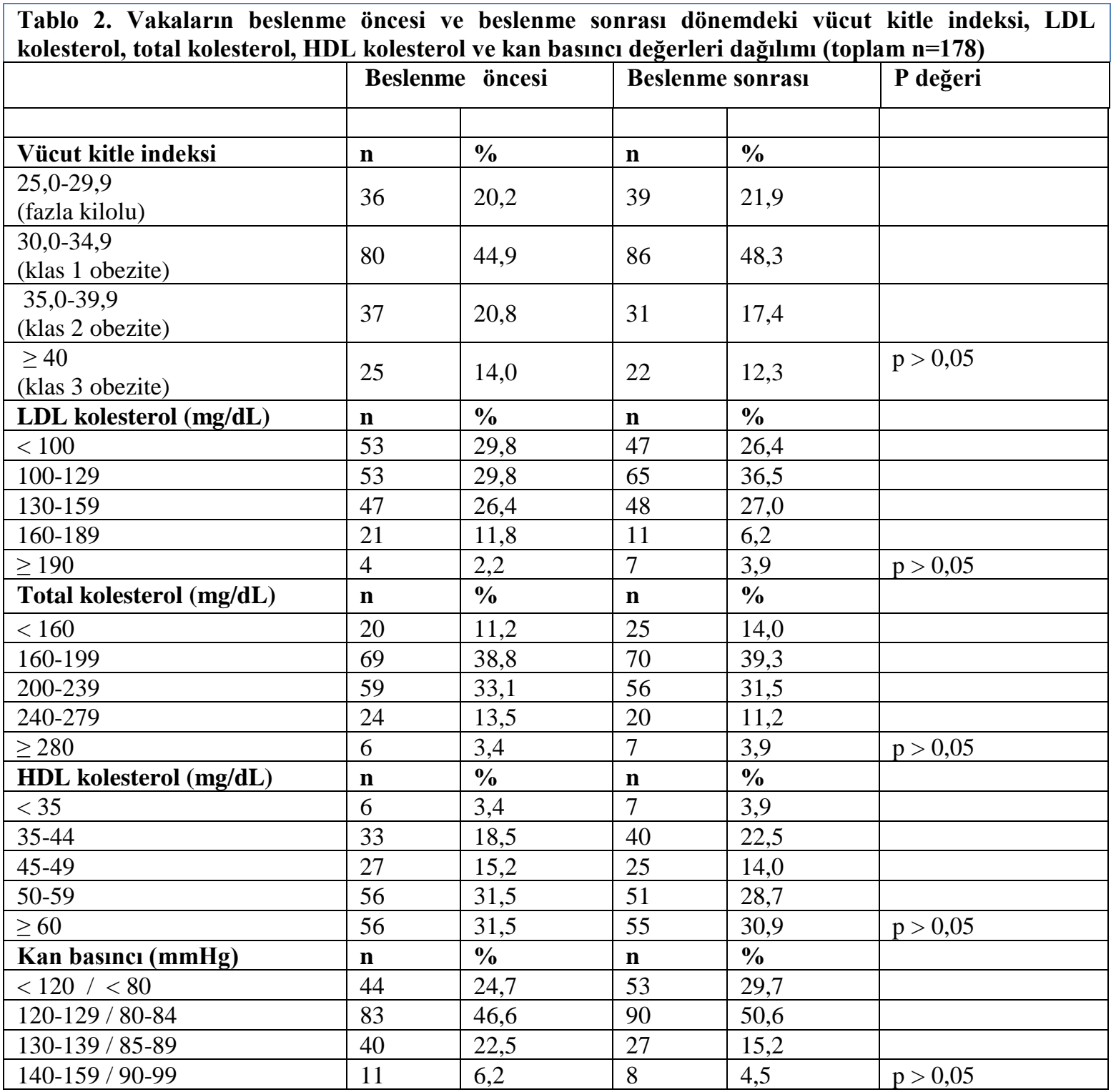

Tablo 3. Vakaların yaş aralıkları ve beslenme öncesi-beslenme sonrası kardiyovasküler hastalık riski* düzeylerine göre dağılımı

\begin{tabular}{|l|l|l|l|l|l|}
\hline & & $\begin{array}{l}\text { Beslenme tedavisi } \\
\text { öncesi } \\
\text { ortalaması } \\
\text { (ortalama } \pm \text { SD) }\end{array}$ & $\begin{array}{l}\text { Beslenme tedavisi } \\
\text { sonras1 risk } \\
\text { ortalamas1 } \\
\text { (ortalama } \pm \text { SD) }\end{array}$ & $\begin{array}{l}\text { Risk } \\
\text { değişimi }\end{array}$ & \\
\hline Yaş aralı̆̆ı & $\mathrm{n}$ & & & & $\mathrm{p}>0,05$ \\
\hline $30-34$ & 22 & $1,0 \pm 0,7$ & $1,0 \pm 0,6$ & -0.0 & $\mathrm{p}<0,05$ \\
\hline $35-39$ & 26 & $1,7 \pm 0,9$ & $1,4 \pm 0,8$ & -0.3 & $\mathrm{p}<0,05$ \\
\hline $40-44$ & 38 & $3,6 \pm 1,9$ & $3,1 \pm 1,8$ & -0.5 & $\mathrm{p}<0,05$ \\
\hline $45-49$ & 22 & $5,2 \pm 2,1$ & $4,8 \pm 2,9$ & -0.4 & $\mathrm{p}<0,05$ \\
\hline $50-54$ & 28 & $9,4 \pm 3,4$ & $7,7 \pm 4,1$ & -1.7 & $\mathrm{p}<0,05$ \\
\hline $55-59$ & 25 & $13,3 \pm 4,8$ & $11,6 \pm 5,2$ & -1.7 & $\mathrm{p}<0,05$ \\
\hline $60-64$ & 17 & $15,6 \pm 5,3$ & $13,2 \pm 5,9$ & -2.4 & \\
\hline
\end{tabular}

* Kardiyovasküler hastalık riski; yaş, cinsiyet, LDL-kolesterol, HDL-kolesterol, kan basıncı, diyabet ve sigara içme parametreleri kullanılarak 10 yıl içindeki kardiyovasküler hastalık riskini öngörmeyi sağlayan Framingham risk skorlamasına göre hesaplanmıştır. 
Obezite ve farklı beslenme uygulamalarının kardiyovasküler risk faktörleri üzerindeki etkilerini araştıran pek çok çalışma kilo vermeyle kardiyovasküler risk faktörlerinin farklı düzeylerde olumlu yönde ve istatistiksel olarak anlamlı düzeylerde değiştiğini göstermiştir. ${ }^{7,8,9} \mathrm{Bu}$ konuda yapılan çalışmalarda uygulanan beslenmenin başarısının değerlendirilmesi için 6-12 ay arasında takipler önerilmektedir.

Tedavi ve yönetim kılavuzlarında $\% 5-10$ arası kilo vermenin metabolik sendrom bileşenleri ve kardiyovasküler hastalık risklerini kontrol altına almada etkili olduğu vurgulanmaktadır.,10 Çalışmamızda vakaların vücut kitle indekslerinde, istatistiksel olarak anlamlı olmasa da, bir miktar azalma tespit edilmiştir. Fakat bu vakalardan hiçbirinde başlangıçta belirlenen 6 aylık kilo verme hedefine ulaşılamamıştır. $\mathrm{Bu}$ konuda yapılmış benzer çalışmalarla kıyaslandığında çalışmamızda uygulanan beslenme tedavisinin vakalara kilo verdirme anlamında başlangıçta hedeflenen etkiyi yeterli düzeyde sağlayamadığı görülmektedir. ${ }^{11,12}$

Beslenme ve bununla ilișkili yaşam tarzı değişikliği önerileri kronik bir hastalık olan obezitenin uzun süreli tedavisinde en etkili tedavi araçlarıdır. Tıpkı diyabet ve hipertansiyonda en etkili ve başarılı ilaç tedavilerine rağmen hedef değerlere ulaşma oranının beklenenin altında olması gibi, kronik bir hastalık olan ve pek çok vakada tedavinin ömür boyu sürmesi gereken obezitede de, hastanın önerilen ilaç dıșı tedavi yaklaşımlarına uyumunu etkileyen hastalık algısı ve psikososyal faktörlerin araştırılması ve müdahale yaklaşımlarının bu faktörlere göre kişiselleştirilmesi başarı oranını artıracaktır.

Çalışmamızda vakaların büyük bir bölümünde kilo azalması \%5'in altında kalmıştır. Vücut ağırlığındaki azalma yeterli olmamasına rağmen ortaya çıkan risk azalması istatistiksel olarak anlamlı düzeylerde bulunmuştur. Bunun nedeni olarak; risk skorlamasında kullandığımız kolesterol, LDL-kolesterol, HDL-kolesterol ve kan basıncının obez vakalarda düşük düzeyde vücut ağırlığı azalmalarında bile olumlu yönde etkilenmesi olduğu düşünülmektedir. ${ }^{1}$ Çalışmada risk skorlaması ve analizi yapılırken vakalar tanıları ve kullandıkları ilaç tedavileri bağlamında incelenmemiştir. Tüm vakaların yaşa göre ortalama risk durumlarını belirledik. Takip altındaki altı aylık süre boyunca vakaların ilaç tedavilerinde, fizik egzersiz durumlarında ve sigara içme durumlarında belirgin değişiklikler olmaması nedeniyle elde edilen sonuçlar beslenme tedavisine bağlanmıştır.

\section{SONUÇ}

Obezite, mücadelesi güç bir kronik hastalıktır. Gelişen ilaç teknolojisine rağmen halâ elimizdeki en güçlü ve etkili yaklaşım, yaşam tarzı değişiklikleridir. Obeziteyle etkili mücadele için, vakaların tek tek muayene edilmesi, değerlendirilmesi ve bireysel tedavi planlamalarının yapılmasının yanı sıra toplumsal düzeyde koruyucu yaşam tarzı değişikliği politikalarının da hayata geçirilmesi gerekmektedir. $\mathrm{Bu}$ konuda başta Finlandiya olmak üzere uygun politikalarla başarı sağlamış pek çok örnek ülke mevcuttur. ${ }^{13}$ Her ne kadar dışarıdan bakıldığında obezite sadece obez vakaların sorunuymuş gibi görünse de gerçekte ortaya çıkardığı risk faktörleri, morbidite ve hastalık yükü bu hastalığı tüm toplumun sorunu haline getirmektedir. Çalışmanın sonuçları sadece kadın popülasyona özgüdür, obezitesi olan erkeklerde yapılan çalışmalarda farklı sonuçlara ulaşılabilir.

\section{KAYNAKLAR}

1. Türkiye Endokrinoloji ve Metabolizma Derneği. Obezite Tanı ve Tedavi Kılavuzu. 5. Baskı. Ankara: Miki Matbaacılık; 2017. p.1117.

http://www.turkendokrin.org/files/OBEZITE20 17 web.pdf. Son Erişim Tarihi: 24.02.2018.

2. Abacı A. Kardiyovasküler Risk Faktörlerinin Ülkemizdeki Durumu. Türk Kardiyol Dern Arş. 2011; 39 Suppl 4: 1-5.

3. Onat A. TEKHARF 2017. 1. Bask1. İstanbul: Logos Yayıncilik; $2017 . \quad$ p.3-8. http://file.tkd.org.tr/PDFs/ TEKHARF2017.pdf. Son Erişim Tarihi: 24.02.2018.

4. Anderson KM, Odell PM, Wilson PWF, Kannel WB. Cardiovascular Disease Risk Profiles. American Heart Journal. 1991; 121(1): 293-2998.

5. Wilson PWF, D'Agostino RB, Levy D, Belanger AM, Silbershatz H, Kannel WB. Prediction of coronary heart disease using risk factor categories. Circulation. 1998;97:183747.

6. Castelli WP. Epidemiology of coronary heart disease: The Framingham Heart Study. Am J Med. 1984; 76:4.

7. Barnard ND, Cohen J, Jenkins DJA, TurnerMcGrievy G, Lise Gloede, et al. A Low-Fat Vegan Diet Improves Glycemic Control and Cardiovascular Risk Factors in a Randomized Clinical Trial in Individuals With Type 2 Diabetes. Diabetes Care 2006; 29(8):17771783.

8. Huijbregts PCW, Feskens EJ, Kromhout D. Dietary Patterns and Cardiovascular Risk Factors in Elderly Men: The Zutphen Elderly Study. Int. J. Epidemiol. 1995;24(2):313-320. 
9. Estruch R, Martinez-Gonzalez MA, Corella D, Sala J, et al. Effects of a Mediterranean-Style Diet on Cardiovascular Risk Factors. Ann Intern Med. 2006;145:1-11.

10. ATP-III:Third report of the National Cholesterol Education Program (NCEP) Expert Panel on detection, evaluation, and treatment of high blood cholesterol in adults (Adult Treatment Panel III). Circulation 2002; 106:3143.

11. Brehm BJ, Seeley RJ, Daniels SR, D’Alessio DA. A Randomized Trial Comparing a Very Low Carbohydrate Diet and a CalorieRestricted Low Fat Diet on Body Weight and Cardiovascular Risk Factors in Healthy Women. J. Clin. Endocrinol. Metab. 2003;88(4):1617-1623.

12. Noakes M, Keogh JB, Foster PR, Clifton PM. Effect of an energy-restricted, high-protein, low-fat diet relative to a conventional highcarbohydrate, low-fat diet on weight loss, body composition, nutritional status, and markers of cardiovascular health in obese women. Am J Clin Nutr 2005;81(6):1298-1306.

13. Vartiainen E, Jousilahti P, Alfthan G, Sundvall J. Cardiovascular risk factor changes in Finland. Int. J. Epidemiol. 2000;29(1):49-56. 